\title{
Lyophilisate for Oral Spray, Suspension Dosage Form
}

National Cancer Institute

\section{Source}

National Cancer Institute. Lyophilisate for Oral Spray, Suspension Dosage Form. NCI

Thesaurus. Code C149639.

Solid preparation for veterinary use consisting of a freeze-dried powder intended to be dispersed in the specified liquid to obtain an oral spray, suspension. 